\title{
LOS DERECHOS DE APROVECHAMIENTO DE AGUAS EN CHILE Y SU MARCO REGULATORIO*
}

\author{
THE WATER USE RIGHTS IN CHILE AND ITS REgUlatory FRAMEWORK \\ LES DROITS D'USAGE DES EAUX AU CHILI ET LEUR \\ CADRE RÉGULATEUR \\ Pablo Aranda Valenzuela*
}

\begin{abstract}
RESUMEN
Este artículo trata sobre la administración del recurso hidrico en Chile a través del mercado. El autor realiza una descripción del sistema regulatorio en materia hídrica a partir del Código de Aguas de 1981 a la fecha, refiriéndose asimismo a las potestades de la agencia asignadora del agua, reflexiona acerca de las fallas que presenta el sistema de mercado en la asignación de las aguas y las características peculiares -únicas en el mundo- de las asignaciones. Para concluir realiza propuestas para un mejor funcionamiento del sistema hidrico, tendientes a una eficiente utilización del recurso hídrico.
\end{abstract}

Palabras Clave: Derecho de aprovechamiento de las aguas - Mercado - Potestades Agencia Asignadora

ABSTRACT

This article analyzes the administration of water resources in the Chilean market. The author describes the normative system regarding hydric resources. The description is based on the Water Code from 1981, considering also the faculties of the water resources allocation agency. The article also addresses the failures of the market system in the allocation of water resources and the unique characteristics of the aforementioned allocations. To conclude, there are some proposals for the better operation of the water resources allocation system in order to give a better use to water resources.

KEY WORDS: Water right - Market - Powers water resources allocation agency

RÉSUMÉ

Il s'agit d'analyser la gestion des ressources d'eaux au sein du marché chilien. D'abord, on fait une description autour de la réglementation sur les questions principales concernant le sujet à partir du Code des eaux de 1981 à ce jour, en étudiant également aux pouvoirs de l'agence de l'attribution de cette ressource; en outre, on réflechit aussi sur les échecs du système de marché dans l'allocation des eaux et ses caractéristiques uniques dans le monde. En conclusion, on fait des propositions pour améliorer le fonctionnement du système des eaux, visant à son utilisation efficace.

MotS CLÉs: Droit d'exploitation des eaux - Marché - Pouvoirs agence de l'attribution

* Artículo recibido el 2 de abril de 2013 y aceptado para su publicación el 21 de agosto de 2013.

** Licenciado en Ciencias Jurídicas y Sociales por la Universidad de Chile. Magíster (c) en Derecho Público por la Universidad de Chile. Actualmente trabaja como Abogado de Proyectos de Energía Andina S.A. Correo electrónico: paranda@energiandina.cl. 


\section{De la asignación de los derechos de aprovechamiento de las aguas ${ }^{1}$ COMO MEDIO DE INTERVENCIÓN Y REGULACIÓN ESTATAL}

El agua es recurso natural, único, finito e indispensable para todo organismo viviente y, para la mayoría de las actividades económicas, el crecimiento de la población y de la economía, estimulan su demanda global. Actualmente existe una sobreexplotación del recurso, situación que obedece a diversas razones, una de ellas se encuentra en la gestión del recurso hídrico.

Chile es uno de los países que optó por el uso del mercado en la administración del recurso hídrico. El Código de Aguas de 1981, creó mecanismos de mercado, basados en la separación de los derechos de aprovechamiento de las aguas de la propiedad de la tierra, fortaleció de manera significativa la propiedad privada, eliminando toda posibilidad de caducar los derechos de agua directamente, por parte de la Administración Pública, suprimiendo toda norma que pudiera debilitar la propiedad, limitando en especial las potestades de la autoridad que pudieran afectarla. De esta manera, aumentó la autonomía privada en el uso de las aguas, favoreciendo los mercados libres de derechos de agua hasta un extremo sin precedentes.

El ordenamiento jurídico vigente, relativo al recurso hídrico, y particularmente el Código de Aguas, aún con las modificaciones de la Ley No 20.017, proyecto de ley que luego de una tramitación de 13 años en el Congreso, intentó mejorar el cuerpo legal existente instaurando algunas normas de carácter ambiental como las que establecieron un "caudal ecológico mínimo", requisito para otorgar derechos de aguas $^{2}$. También se estableció el pago de una patente anual por el no uso de derechos de aprovechamiento, así como el otorgamiento de potestades más contundentes a la Dirección General de Aguas, en materia de distribución de las aguas únicamente en situaciones excepcionales de escasez y disponibilidad. Sistema que se basa de manera irrestricta en la protección de la libre determinación y ejercicio del titular de su(s) derecho(s) de aprovechamiento de agua en la actividad que desee.

La falta de exigencias o imposiciones que representen condiciones o requisitos para la constitución y ejercicio, de los derechos de aprovechamiento de las aguas, hacen que la utilización de un bien de uso público $^{3}$ quede regulada casi exclusiva-

\footnotetext{
${ }^{1}$ El Código de Aguas clasifica en primer término a las aguas en marítimas y terrestres, para luego declarar que la legislación contenida en él sólo es aplicable a las aguas terrestres. Sin embargo, contiene además otras clasificaciones, en que se considera su situación en el espacio, es decir si se trata de aguas superficiales y subterráneas; su movilidad, aguas corrientes y detenidas; y su calificación jurídica en cuanto bien, si es mueble o inmueble. Para efectos del presente documento nuestro análisis dirá relación con las aguas terrestres.

2 Programa Chile Sustentable (2010). Marco jurídico para la gestión del agua en Chile: Diagnóstico y Desafíos", Santiago, p. 7. Disponible en: <http://www.chilesustentable.net/wp-content/uploads/kalins-pdf/ singles/marco-juridico-para-la-gestion-del-agua-en-chile-diagnostico-y-desafios.pdf>.

${ }^{3}$ Así lo dispone el artículo 595 del Código Civil. Asimismo, se reafirma este carácter, de conformidad a lo señalado por el Código de Aguas en su artículo 5.
} 
mente desde una perspectiva económica y orientada al mercado, con una mínima intervención estatal.

Luego de 30 años, aún con las modificaciones antes reseñadas, la regulación de la asignación de los derechos de aprovechamiento no ha logrado abordar de manera adecuada el manejo integral del recurso, particularmente, en la coordinación de usos múltiples, la internalización de externalidades económicas y ambientales, y en el manejo integral de cuencas.

Particularmente, las aguas subterráneas son muy importantes como fuente de agua potable, tanto para la población urbana y rural, como también para la agricultura y la actividad minera en algunas regiones de nuestro país. Además, su potencial de almacenamiento y uso conjunto con las aguas superficiales, le otorgan un enorme valor para hacer frente al cambio climático ${ }^{4}$. El concepto de gestión integrada de recursos hídricos se plantea como una respuesta para el aprovechamiento óptimo del conjunto de las fuentes hídricas, sin embargo, en Chile esta integración no ha sido aplicada a nivel normativo ${ }^{5}$.

La pregunta genérica que aflora ante estas circunstancias, es si existe la posibilidad de mejorar la gestión del recurso hídrico, cuestión que, sin duda, encierra un conjunto de elementos, que en primer término conviene clarificar y, cuyo abanico de respuestas posibles no sólo es bastante divergente, sino que contempla también diferencias de intereses tanto ideológicos como materiales.

\section{Motivos QUe JUSTIFICARÍAN INTERVENIR EN EL ACTUAL SISTEMA REGULATORIO DEL AGUA}

El Derecho Administrativo, en la actualidad, regula la relación no sólo entre la administración pública y los ciudadanos, sino que también entre éstos y los mercados. Efectivamente, el establecimiento de los procesos de privatización y desregulación que han dominado, queramos o no, los últimos treinta años en Chile, han vuelto a colocar sobre el tapete la vieja discusión de qué le corresponde realizar al Estado y hasta dónde .

Resulta prudente preguntarse primero, si la regulación es la medida más apropiada para el caso específico que uno está considerando. En efecto, esta medida tiene por objeto resolver aspectos claves. ¿¿Por qué el Estado debe actuar de una u

\footnotetext{
${ }^{4}$ Banco Mundial (2011). Diagnóstico de la gestión de los recursos hídricos. Departamento de Medio Ambiente y Desarrollo Sostenible.

${ }^{5}$ La legislación chilena en materia de derecho de aprovechamiento de las aguas, reglamenta las aguas terrestres atendiendo en forma independiente las fuentes superficiales y subterráneas. En un esfuerzo por remediar la falta de integración del recurso hídrico, se crea en 1999 la Política Nacional de Recursos Hídricos y el 2007 la Estrategia Nacional de Gestión Integrada de Cuencas Hidrográficas. Lamentablemente, hasta ahora, sólo han sido experiencias piloto, debido a su falta de implementación efectiva a nivel normativo.

${ }^{6}$ Cordero Vega, Luis (2006). "Los contratos públicos como medio de intervención y regulación estatal”. Revista de Derecho Administrativo Económico, No 17, p. 4.
} 
otra forma? ¿Por qué el Estado debe velar para la utilización racional y sustentable del recurso hídrico? ¿Existen actualmente, herramientas jurídicas e institucionales correctas para tales fines?

Las respuestas a estas preguntas, pueden ir básicamente en dos direcciones; en primer lugar, hacia aspectos normativos, considerando que existen determinados valores, elementos definidos por la Constitución y el ordenamiento jurídico en general, que el Estado debe proteger. En segundo lugar, hacia aspectos de carácter sustantivos o económicos, en los cuales será posible observar si los elementos del mercado funcionan efectivamente como la teoría indica o no, y que producto de esa circunstancia deberemos apuntar a corregir las fallas existentes.

En materia de la regulación de la asignación y administración del recurso hídrico existe, a mi juicio, la clara posibilidad de dar respuesta, y justificar una intervención desde las dos ópticas. La agencia asignadora-Dirección General de Aguas-, actúa dentro del marco regulatorio e institucional, determinado principalmente por lo dispuesto en el Código de Aguas y la Resolución Exenta de la Dirección General de Aguas No 425/2007, que dispone las normas de exploración y explotación de aguas subterráneas.

\section{Aspectos generales del sistema de mercado}

EN SU ROL ASIGNADOR

El sistema creado por la actual legislación de aguas, tiene como objetivo esencial la creación de un mercado de aguas que cumpla el rol asignador de los recursos, donde los derechos de propiedad se definen como privados y transables ${ }^{7}$.

Como características principales del sistema se pueden señalar las siguientes:

- Se reconoce el libre acceso de los derechos de agua. En efecto, no hay en nuestro sistema usos determinados o casuales especiales que habiliten a pedir derechos sobre las aguas o que determinen la preferencia de unos solicitantes sobre otros ${ }^{8}$.

- Los derechos de aprovechamiento de las aguas tienen directa protección constitucional mediante la extensión de la garantía de la propiedad, artículo 19 número 24 de la Constitución Política de la República.

- Producto de la modificación del Código de Aguas de 1981, mediante la Ley No 20.017, existe un régimen de amparo especial, mediante el pago de una patente, aplicables a quienes no usan efectivamente su derecho de aprovechamiento de aguas. De este modo, el derecho de aprovechamiento sólo se pierde, por medio de las formas contempladas en el derecho común. No existe forma de caducidad

7 Para una revisión mas detallada, Monroy Cely, Daniel (2003). El mercado de las aguas: la libre transmisibilidad de los derechos de aguas en Chile y su propuesta regulatoria a las demás legislaciones. Memoria para optar al grado de Magíster en Derecho, Facultad de Derecho, Universidad de Chile.

${ }^{8}$ En el evento que existan varias solicitudes se subastan a través del procedimiento de remate. 
administrativa de los derechos de aprovechamiento, situación que permite que sus titulares puedan no utilizar de manera efectiva el recurso hídrico.

- Posterior a las recientes modificaciones legales en materia hídrica, si bien el rol del Estado se ha hecho más vigoroso, sin que se pueda afirmar que se trate de un Estado interventor en esas materias, o que haya reemplazado al mercado como asignador de recursos. La intervención estatal, ha tenido como objetivo evitar las distorsiones que han impedido el normal funcionamiento del mercado y lograr una mayor protección de los acuíferos, situación que aún persiste.

- La fiscalización del uso del recurso, de acuerdo al título de los derechos de aprovechamiento de las aguas, se ha entregado a los propios usuarios, mediante las organizaciones de usuarios de carácter privado. En relación a este aspecto, es importante destacar que a partir de las reformas efectuadas a la legislación de aguas del año 2005, las juntas de vigilancia tienen facultades para incorporar entre sus miembros a los usuarios de aguas subterráneas. Sin embargo, para esto efectos, aun no se ha redactado una normativa que permita diseñar mejor el funcionamiento de las Juntas de Vigilancia en estos aspectos 9 .

- No se requiere pagar canon ni tributo para la obtención originariamente de los derechos de aprovechamiento de las aguas ${ }^{10}$, otorgados por la Dirección General de Aguas, organismo encargado por ley de constituir originariamente derechos de aprovechamiento sobre aguas existentes en fuentes naturales (río, esteros, lagos, acuíferos etc.).

- Se establece la libre transferencia de los derechos de aprovechamiento de las aguas, definidos como privados y transables, se determinan las condiciones primarias para el desenvolvimiento del mercado. Podemos apreciar, que la concepción impuesta por la legislación de aguas, aún luego de la reforma del año 2005, es marcadamente liberal, pues decidió que la correcta distribución de las aguas y sus derechos debía ser regulada por el mercado.

Pablo Jaeger, expresa en torno al régimen jurídico de las aguas, "en sus rasgos principales, podemos caracterizar de la siguiente forma el derecho de aguas chileno: sólido derecho de propiedad sobre los derechos de aprovechamiento, y no sobre el agua misma; plena autonomía privada en el uso y gestión del recurso; gratuidad en la obtención de los derechos de aprovechamiento y durante la permanencia de ellos en el patrimonio particular; inexistencia de preferencias en la constitución del derecho de aprovechamiento, debiendo recurrirse al remate de los mismos cuando

${ }^{9}$ COMISIÓN DE AgUAS (2011). Temas prioritarios para una política nacional de recursos hídricos. Instituto de Ingenieros de Chile.

${ }^{10}$ Esta característica es singular y llama poderosamente la atención, se entrega un bien nacional de uso público a un privado, el cual, una vez constituido su derecho de aprovechamiento se encuentra autorizado para vender ese derecho y recibir una contraprestación en dinero por la utilización de un bien que teóricamente sigue siendo de la nación, ¿̨no existiría enriquecimiento ilícito?, ¿no sería justo que la Dirección General de Aguas reciba un canon o tributo por la asignación de este derecho de aprovechamiento? o ¿reciba un porcentaje de cada venta de los derechos de aprovechamiento? 
haya más de un interesado por las mismas aguas; $y$, finalmente, escasas atribuciones de la autoridad pública en la gestión y planificación de los recursos hídricos ${ }^{11 "}$.

\section{Potestades de la AgenCia ASIGNADOra DEL RECURSO HÍDRICO}

La Dirección General de Aguas ${ }^{12}$, organismo dotado de personalidad de derecho público, cumple en primer término la función general de control de las fuentes de agua, teniendo a su cargo la confección y mantención de un catastro público de las aguas, en que constan todas las fuentes permanentes de agua con la indicación de los derechos concedidos. Las facultades de la agencia se encuentran establecidas en los artículos 299 y siguientes del Código de Aguas. La doctrina mayoritaria ha estimado que las facultades son insuficientes para el control efectivo del manejo de las aguas, especialmente el desarrollo de las aguas superficiales ${ }^{13}$.

Esta situación no parece ser novedad, sino más bien una constatación del sistema instaurado a través del Código de Aguas de 1981, el cual eliminó las disposiciones relativas a la facultad del Estado para establecer un uso efectivo y beneficioso, preferencia de usos prioritarios, caducidad por no uso o cualquier otra medida que restringiese o limitase la plena libertad del titular sobre su derecho de aprovechamiento. La debilidad en las facultades de la DGA, es un fiel reflejo de un sistema de aguas con un carácter eminentemente mercantilista.

La DGA debe conceder los derechos de aprovechamiento de aguas que se solicitan, siempre que sea procedente desde un punto de vista legal -producto de la modificación del Código de Aguas, a través de la Ley No 20.017-, que exista disponibilidad del recurso y no se afecten derechos de terceros. Ahora bien, estos derechos de aprovechamiento podrán ser consuntivos o no consuntivos. Los primeros facultan a su titular para consumir totalmente las aguas en cualquier actividad ${ }^{14}$, los segundos le permiten emplear el agua sin consumirla y lo obligan a restituirla en la forma que determine el acto de constitución.

Cabe hacer presente que la DGA, al constituir un derecho de aprovechamiento de aguas, ejerce una potestad que es reglada, vale decir, una vez que se ha constatado que concurren los requisitos previstos por la ley, el órgano administrativo debe acceder a la solicitud, en esta materia rige lo que se denomina por la doctrina como discrecionalidad reducida casi a cero. Es la ley la que ha prefijado los requisitos,

\footnotetext{
${ }^{11}$ Jaeger Cousiño, Pablo (2004). "El innovador derecho de aguas chileno". Revista del Abogado, No 31, p. 14.

12 En adelante DGA.

13 Mayor detalle de la discusión, Segura Riveiro, Francisco (2006). Derecho de Aguas. Santiago: LexisNexis.

${ }^{14}$ Rendic Véliz, Dinko (2011). "Derechos de aguas y pueblos indígenas. Especial referencia a los derechos ancestrales de la Comunidad Indígena de Toconce”. Santiago: Librotecnia, p. 110.
} 
y la autoridad no puede, por su voluntad, agregar otros nuevos, sin quebrantar la juridicidad ${ }^{15}$.

La limitación de las facultades de la DGA, se reflejan en que las funciones de gestión y planificación son más bien de carácter nominal propiamente, así como en sus labores de policía y vigilancia. La DGA tampoco puede involucrarse en la distribución de la aguas, como regla general, ni en la resolución de conflictos.

La intervención de la DGA en la administración de los recursos hídricos está delimitada al ámbito de las competencias que le ha entregado la ley, y de manera particular, el Código de Aguas. Es así como el sistema chileno, establece que gran parte de las tareas de organización y administración de los recursos hídricos ya otorgados a privados a título de derechos de aprovechamiento de aguas, sean ejercidos por éstos, en la práctica, a través de los diferentes tipos de organizaciones de usuarios, sean constituidos legalmente o no ${ }^{16}$.

Dentro de las atribuciones más relevantes de la agencia asignadora originariamente de los derechos de aprovechamiento, dice relación con el ejercicio de labores de policía y vigilancia de las aguas en los cauces naturales de uso público, impidiendo que en estos se construyan, modifiquen o destruyan obras sin la autorización previa del servicio o autoridad a quien corresponde aprobar su construcción o autorizar su demolición o modificación. Respecto de esta atribución, la doctrina mayoritaria ha señalado que este rol no es cumplido a cabalidad por la DGA, debido principalmente a falta de recursos económicos adecuados y de atribuciones de la autoridad en estas materias ${ }^{17}$.

La reforma del año 2005, entregó nuevas atribuciones a la DGA, las cuales se encuentran señaladas en los artículos 299 y siguientes del Código de Aguas, que establecen que en el evento de que no exista una junta de vigilancia legalmente constituida, la agencia asignadora podrá impedir que se extraigan aguas de los cauces sin título o en mayor cantidad que la que le corresponda al titular del derecho, pudiendo incluso recurrir a la fuerza pública, de conformidad con lo dispuesto en el artículo 138 del Código de Aguas. También el control se extiende al funcionamiento de las restantes organizaciones de usuarios, situación que antes de la modificación, estaba restringida sólo a la Junta de Vigilancia.

En épocas de sequías extraordinarias, las facultades de la DGA aumentan ostensiblemente, pudiendo en tal evento declarar zona de escasez. El alcance de esta medida se extiende a toda fuente natural, incluyendo también las aguas subterráneas. Esta regla podrá variar en atención a la gravedad de la situación de las aguas,

15 Vergara Blanco, Alejandro (2007). "Potestades administrativas para denegar solicitudes de derechos de aguas subterráneas y retroactividad”. Revista Chilena de Derecho, Vol. 34, No 1, pp. 153-159.

${ }^{16} \mathrm{El}$ artículo 186 y siguientes del Código de Aguas, definen y establecen las atribuciones de las diversas organizaciones de usuarios de aguas superficiales y subterráneas.

${ }^{17}$ En el mismo sentido, BAUER, Carl J. (2004). Canto de sirenas, El derecho de aguas chileno como modelo para reformas internacionales. Bilbao: Bakeaz. 
de esta forma la DGA puede tomar el control de las fuentes naturales, en el caso de declaración de sequía extrema. Asimismo se permite a la agencia la suspensión de las facultades de las juntas de vigilancia y el seccionamiento de los ríos.

Declarada la zona de escasez por un determinado período, el cual no puede superar los seis meses, la DGA puede autorizar extracciones de aguas superficiales y subterráneas desde cualquier punto, sin la necesidad de constituir un derecho de aprovechamiento y sin limitación del caudal ecológico, de acuerdo con lo dispuesto en el artículo 129 inciso $1^{\circ}$ del Código de Aguas. Asimismo podrá adoptar, en estado de zona de escasez, todas las medidas restrictivas sin someterse a las formalidades que establece el Título I del Libro Segundo del Código de Aguas. Esta supone una efectiva suspensión temporal de los derechos de dominio respecto de los titulares. La DGA en uso de las facultades de distribución, debe repartir las aguas de manera proporcional al derecho de cada uno, de acuerdo a los caudales disponibles.

En la práctica, son muy pocas las veces en que declarada la zona de escasez, la DGA procede a redistribuir efectivamente las aguas para minimizar los daños de una sequía. La explicación se encuentra en el Código de Aguas, en el evento que un titular de derechos de aprovechamiento de agua reciba menos de lo que le correspondería de conformidad a las disponibilidades existentes, tiene derecho a ser indemnizado por el Fisco. En términos sencillos, lo que hace esta disposición es tornar muy costoso cualquier error en que incurra la DGA al intervenir la cuenca y redistribuir derechos de aprovechamiento de agua; tan costoso que, finalmente, la DGA en la mayoría de los casos opta en definitiva por no hacerlo.

Otra de las atribuciones de la DGA, de acuerdo a lo dispuesto en el artículo 62 del Código de Aguas, puede, a petición de uno o más titulares de derechos de aprovechamiento, decretar la reducción temporal de la explotación de las aguas subterráneas, cuando esta situación genere un perjuicio a los titulares de derechos de aprovechamiento sobre las mismas aguas subterráneas. En tal evento, la DGA ordenará que se reduzcan los derechos constituidos por las aguas, a prorrata entre todos los usuarios por el plazo que determine, con el objeto de la recuperación del recurso. El artículo 30 de la Resolución Exenta No 425/2007, fija los criterios para acoger la solicitud.

Por otra parte, en virtud de lo dispuesto en el artículo 63 del Código de Aguas, la DGA podrá declarar zonas de prohibición ${ }^{18}$. Ésta se realiza a través de declaración fundada y para la protección del acuífero, que debe ser publicada en el Diario Oficial, su efecto, como lo indica su nombre, es prohibir futuras explotaciones en el acuífero,

${ }^{18}$ Conviene precisar que tanto en las zonas de prohibición como asimismo en las áreas de restricción, la Contraloría ha señalado de manera sistemática en los Dictámenes Nos 10969/2003, 56046/2003 5215/2006, que esta atribución sólo tendrá efecto, una vez dictada la resolución y publicada en el Diario Oficial, en las solicitudes de derechos de aprovechamiento que se encuentren en proceso antes de la publicación del Diario Oficial. 
Esta declaración genera la obligación de constituir una comunidad de aguas formada por todos los usuarios de aguas subterráneas que comprenden esta zona. La facultad es privativa de la DGA, sólo se ejerce de oficio, de conformidad a lo dispuesto en el artículo 36 de la Resolución Exenta de la Dirección General de Aguas No 425/2007, cuando se establezca un peligro de contaminación del acuífero, agotamiento del mismo por sobreexplotación o perjuicios a derechos de aprovechamiento legalmente constituidos en zonas de recuperación de cauces naturales.

Asimismo, de acuerdo con lo dispuesto en el artículo 65 del Código de Aguas, la DGA puede establecer de oficio o a petición de usuarios interesados la declaración del área de restricción. Se considerará como interesados a aquellos para los cuales exista un grave riesgo de disminución de un determinado acuífero, generando el respectivo perjuicio a los derechos de terceros establecidos con anterioridad. Procede cuando en un sector hidrogeológico de aprovechamiento común, existe riesgo de una grave disminución de un determinado acuífero, con el consiguiente perjuicio de derechos de terceros ya establecidos en él. Una vez que se decreta, se origina una comunidad de aguas entre todos los usuarios del acuífero, pero la consecuencia más relevante es que a partir de esa declaración, la DGA solo puede otorgar derechos de agua provisionales sobre el acuífero. Sin embargo, por regla general, esos derechos provisionales devienen en definitivos al cabo de cinco años, a menos que la DGA -entre su otorgamiento y antes del cumplimiento de ese plazo-acredite perjuicios a terceros o bien que un tercero, por sí mismo, acredite daño.

Finalmente la falta de atribuciones de la DGA, se observa en que el actual sistema de gestión de las aguas, carece de una visión integradora, separando las responsabilidades de la asignación de los derechos de aprovechamiento, de la gestión del recurso hídrico. En esa misma línea, no hay una integración en la administración y gestión de los recursos hídricos.

\section{Problemas asociados al funcionamiento del mercado de los DERECHOS DE APROVECHAMIENTO DE LAS AGUAS}

Los problemas asociados al funcionamiento de un mercado de este tipo, son aquellos que están estrechamente asociados al diseño del sistema, los más significativos son ${ }^{19}$ :

- Falta de información adecuada y oportuna: Para el funcionamiento adecuado de un mercado, se requiere la existencia de información adecuada para que oferentes y demandantes de un bien, puedan conocer los precios de transacción. En la

\footnotetext{
${ }^{19}$ Conviene precisar que existe un mayor número de problemas relativos al funcionamiento del mercado de las aguas, los cuales pueden ser revisados en, Donoso, Guillermo; Jouravlev, Andrei; Peña, Humbert y ZegarRa, Ernesto (2004). "Mercados (de derechos) de agua: experiencias y propuestas en América del Sur". En: Serie Recursos Naturales e Infraestructura, No 80, CEPAL, pp. 42-45. Disponible en: <http://www. bvsde.paho.org/bvsaca/fulltext/mercados.pdf> [consulta: 10 noviembre 2011].
} 
medida que falta información adecuada hay una percepción incompleta del valor asignado al derecho, lo que dificulta las transacciones. Este problema de falta de información ha sido otro de los motivos para que se modificara el artículo 122 del Código de Aguas, mediante las Leyes No 20.017 y 20.099, en el sentido de establecer la obligatoriedad del registro de los derechos de aprovechamiento en el Catastro Público de Aguas, con el fin de contar con la información adecuada acerca de la ubicación del punto de captación de los derechos, el caudal expresado en volumen por unidad de tiempo y las características esenciales del derecho.

- Asimetría en la disponibilidad de la información entre diferentes interesados por derechos de aguas de una misma cuenca hidrográfica: Aceptando que el adecuado funcionamiento de un mercado perfecto se basa en que todos los participantes dispongan de la misma cantidad y calidad de información, el mercado de los derechos de aprovechamiento en Chile, no es entonces un mercado perfecto. Resulta innegable, por ejemplo, que una gran compañía minera podrá disponer de una muchísima mayor cantidad de información que un pequeño agricultor que coincida con ella como interesado por aguas de una misma cuenca. Esta situación genera sin duda una condición de claro menoscabo para "el competidor con menos información".

- Inconsistencia entre los derechos nominales y los derechos que efectivamente se ejercen: Esta situación se presenta particularmente en los casos de los derechos otorgados al amparo de anteriores legislaciones, aquellos derechos consuetudinarios y en algunos casos, en relación con los derechos de aprovechamiento de aguas subterráneas. Esta inconsistencia también es una barrera a las transacciones por falta de definición adecuada de los derechos.

- Especulación y acaparamiento de los derechos: Existe un problema generalizado de acaparamiento de derechos sin utilización, lo que ha creado de hecho una barrera de entrada para nuevos inversores en proyectos asociados a la utilización de los recursos hídricos ya concedidos. Precisamente, la creación de un costo de alternativa por medio de un impuesto como el de la patente por no uso, tiene por objeto incentivar a que los derechos de aprovechamiento no utilizados sean en algún momento transferidos hacia mejores y más eficiente usos. En el mismo sentido, juegan las nuevas disposiciones legales incorporadas por la Ley No 20.017, relativas a la obligación de justificar el uso de los derechos de aprovechamiento que se solicitan.

- Inadecuada resolución de conflictos: Mecanismos inadecuados de resolución de conflictos pueden desincentivar las transacciones. En la actualidad existen tres vías formales de resolución de conflictos en el sistema del Código de Aguas, una es la vía judicial, mediante el ejercicio de acciones establecidas en el ordenamiento jurídico; la vía administrativa, a través de la solicitud de intervención de la autoridad administrativa -DGA- y finalmente, un mecanismo de escasa aplicación práctica es el arbitraje al interior de las organizaciones de usuarios. 


\section{EXTERNALIDADES QUE EVIDENCIAN UN MAL FUNCIONAMIENTO \\ DEL MERCADO ASIGNADOR}

El concepto de la externalidad se refiere a los efectos que sufren una o varias personas, producto de acciones u omisiones de otras, sin que el generador de ésta reciba una compensación en el caso de beneficios (externalidad positiva), ni pague un resarcimiento en el caso de los daños (externalidad negativa). Una externalidad es un costo que se impone a otros, o un beneficio conferido a otros, cuya recompensa no puede obtenerse ${ }^{20}$.

La concepción operacional del mercado se configura bajo la premisa de que los únicos favorecidos o beneficiados son aquellos que participan en las transacciones. Este esquema conceptual resulta poco aplicable en el caso del agua, pues cualquier uso o abuso sobre ella, afecta de manera directa o indirecta, tanto a los titulares de los derechos de aprovechamiento, como a todos aquellos que se relacionan de alguna forma con las aguas de una misma cuenca.

Desde la perspectiva económica convencional -paradigma en el cual se sustenta el Código de Aguas-, no considera la contaminación como resultado de una acción de carácter antisocial, merecedor de un reproche, sino que se entiende como una respuesta natural de los individuos racionales que buscan un interés propio ${ }^{21}$.

Si bien se ha progresado en el tema de la contaminación del agua, mediante la dictación de normas de emisión y de normas de calidad de las aguas, ocurre que las multas aplicadas no son lo suficientemente duras o estrictas para evitar que se deje de contaminar. Si se presta atención desde el punto de vista económico, para el agente contaminador muchas veces es más rentable seguir produciendo y contaminando, asumiendo sanciones de carácter pecuniario, que asumir las externalidades.

\section{Respuestas a las interRogantes de JUSTIFICACión, CONCLUSIONES Y PROPUESTAS}

Luego de pasar someramente sobre los ejes en los cuales se asienta el sistema de asignación de derechos de aprovechamiento de aguas, corresponde dar respuesta a las interrogantes planteadas al inicio del presente artículo.

Desde una mirada normativa y, teniendo presente la calidad de bien nacional de uso público, de conformidad con nuestro ordenamiento jurídico, cabe señalar, que el uso del agua adquiere una connotación distinta o un trato diferenciado, respecto a los demás bienes de la misma naturaleza jurídica, en el sentido que reconoce a sus titulares la propiedad sobre los derechos de aprovechamiento. Esta

${ }^{20}$ López Santa María, Jorge (1998). Los Contratos. Parte general. T. I, Santiago: Editorial Jurídica de Chile, p. 20.

${ }^{21}$ En el mismo sentido, Revesz, Richard (1997). "Foundations of Environmental Law and Policy". Foundation Press, South California: LexisNexis. 
particular consideración del recurso hídrico, se encuentra ratificada por nuestra Carta fundamental y por sentencia del Tribunal Constitucional ${ }^{22}$.

La doctrina señala que las aguas se encuentran dentro de los bienes de dominio público natural o necesario ${ }^{23}$. Debido a esto, el ordenamiento le otorga un régimen especial, así como al resto de los demás bienes nacionales de uso público. De lo cual, se desprende que a partir de su naturaleza jurídica, se asignaría dos características centrales: a) imposibilita la apropiación privada del recurso, desde la óptica del tráfico jurídico; y, b) concede al Estado, representado por la administración pública, potestades o facultades regulatorias relativas a las actividades que realicen los privados en torno al agua.

La titularidad del dominio público se concretiza en la Administración del Estado, quien será la responsable de custodiar que el recurso hídrico se utilice de manera adecuada según las necesidades públicas. Para dar cumplimiento a los deberes señalados, la DGA debe contar con atribuciones permanentes.

De lo señalado anteriormente, se desprende que, en relación al dominio de las aguas, la Administración debiese estar dotada de ciertas potestades tendientes a regular el uso y garantizar el cumplimiento de las necesidades públicas.

Sin embargo, bajo el actual régimen de aguas, la autoridad no puede hacer demasiado para mejorar el uso del recurso, con miras a satisfacer el bien común, debido a que todo o gran parte está en manos del mercado. El Estado se ha desligado completamente de su deber de velar por el buen manejo y aprovechamiento del agua, en aras del desarrollo económico, situación que ha generado serios problemas ambientales y sociales.

La falta de potestades y atribuciones, que, a la luz de lo descrito precedentemente, debiera de manera natural asumir el titular del dominio público, ha generado que se desnaturalice el verdadero alcance y sentido de los bienes nacionales de uso público, lo que trae como consecuencia que la Administración ha infringido el deber prestacional que le corresponde en ordenar y velar por el interés general ${ }^{24}$.

Atendidas las características de las aguas y su naturaleza de bien nacional de uso público, los actos de constitución de los derechos de aprovechamiento deben ser interpretados y ejercidos en forma tal que permitan el aprovechamiento más eficiente y beneficioso de los recursos hídricos. Esto debido a que tras la función social de la propiedad subyacen ciertos imperativos de solidaridad social que obligan a sacrificar intereses individuales, bajo determinados presupuestos, en beneficio de la colectividad. La imposición de limitaciones a los derechos de aprovechamiento de las aguas está lejos de ser inconstitucional, sino que se condice, plenamente con los derechos y garantías fundamentales establecidas en la Constitución, como

${ }^{22}$ STC Rol No 260, 13 de octubre de 1997.

${ }^{23}$ Ejemplo de estos serían las playas, ríos, mar, aire. MontT Oyarzún, Santiago (2002). El dominio público. Estudio de su régimen especial de protección y utilización. Santiago: ConoSur-LexiNexis.

${ }^{24}$ Montt Oyarzún (2002), p. 146. 
el derecho a la vida, artículo 19 No 1 , y el derecho a vivir en un medio ambiente libre de contaminación, artículo 19 № 8.

Parece evidente manifestar que el funcionamiento del mercado de las aguas, es inadecuado y presenta fallas, las que fueron mencionadas en el apartado anterior. Esta situación permite justificar una intervención mayor a la que actualmente realiza la agencia encargada, aplicando la teoría clásica del interés público o funcionalista de la regulación ${ }^{25}$.

Lo anterior motiva algunas interrogantes relacionadas con la eficiencia del sistema regulatorio y el real aprovechamiento de la capacidad reguladora del Estado, para velar efectivamente por el uso racional y sustentable de las aguas.

\section{1. ¿Existen hoy herramientas juridicas que utilizadas de mejor forma puedan potenciar la capacidad reguladora del Estado?}

La reforma del año 2005, la Ley No 20.017, introdujo determinadas facultades para solucionar ciertos aspectos relativos a la variabilidad de las cantidades de las aguas disponibles en las diferentes cuencas. Estas reformas permitieron que el rol del Estado se hiciera más vigoroso, pero todavía imposibilitado de adquirir una capacidad de interventor, ni tampoco de constituirse en una alternativa al mercado como asignador de estos recursos. Prueba de lo anterior, es que las mayores facultades asignadas a la DGA, se pueden aplicar en su gran mayoría sólo para situaciones especiales o de excepción, como por ejemplo, épocas de sequía extraordinaria o inexistencia de juntas de vigilancia.

Lamentablemente, en la actualidad, a partir de la normativa vigente, se maneja de forma separada las aguas superficiales de las subterráneas, a pesar de que estas forman parte de un solo sistema hidrológico. Sumado a la separación de las responsabilidades en la asignación, a cargo de la DGA y la gestión del recurso en manos de los detentores de los derechos de aprovechamiento de las aguas, no permiten realizar una gestión eficiente de los recursos hídricos, responder de manera eficiente y oportuna a la creciente demanda y competencia por el agua.

Sumado a las implicancias del modelo de mercado como marco regulatorio que establece el Código de Aguas. En tanto modelo, su objetivo es que el recurso propenda a su uso más valioso. Esa meta lleva a que para nuestra legislación de aguas, sea indiferente el uso que pretenda dársele al recurso, lo que se torna particularmente complejo en situaciones de escasez que no llegan aun al punto de constituir una sequía extraordinaria. En éstas, aun cuando exista la necesidad de garantizar una cantidad de agua mínima necesaria para el consumo humano, la autoridad no cuenta con atribuciones ni las potestades para preferir este uso por sobre otros. En otras palabras, no hay en el Código de Aguas normas que determinen una prelación entre los diversos usos que se le pueden dar al recurso hídrico.

25 Cordero Vega (2006), p. 4. 


\section{2. ¿Cómo es posible que el Estado vele efectivamente por el uso racional y sustentable de las aguas?}

A treinta años de la implementación de este sistema, se han creado, fortalecido y concentrado los derechos de aprovechamiento ya asignados en grupos de interés poderosos e influyentes, situación que no parece discutible. Sin embargo, a la luz de lo expresado, existe la necesidad de propender a nivel mundial a la utilización racional y sustentable del recurso. Si miramos las experiencias comparadas, la asignación de derechos se realiza bajo diferentes modalidades, pero con elementos comunes; derechos sujetos a condición, tiempo o a un uso o requerimiento demostrado y previamente justificado, que debe considerar tanto la necesidad, como la disponibilidad presente y especialmente futura de un bien que se torna cada vez más escaso.

Por otra parte, es necesario subsanar el hecho de que se asigne de manera gratuita derechos de aprovechamiento de aguas a los privados, quienes posteriormente pueden enriquecerse a través de la venta de esos derechos, sin haber realizado ninguna contraprestación efectiva. Siendo un bien nacional de uso público es imprescindible que se reciba un canon o tributo, sea al momento de la asignación del derecho que realiza la DGA o cada vez que se realice una venta se reciba un porcentaje de ella.

A nivel interno, parece muy complejo establecer restricciones a los derechos ya establecidos, aun cuando nuestra carta fundamental autorice instaurar ciertas restricciones que no afecten la esencia del derecho, atendiendo a fines sociales y ambientales. Lo más realista es establecer condiciones especiales como el pago de tributos por la asignación, o límites de tiempo como una forma de propender a usos racionales y sustentables, fiscalizados por una agencia asignadora empoderada de manera real en su rol.

Se hace necesaria una intervención estatal, que tenga por objeto regular el mercado, debido a que el paradigma de mercado perfecto, en lo que dice relación con el agua no ha funcionado. Se requiere una enmienda de las imperfecciones del mercado del agua, situación que por lo demás, ya ocurre en la mayoría de los países europeos y estados federales norteamericanos. Particularmente, en materia de conductas abusivas y la falta de la internalización de las externalidades negativas, donde el rol de la DGA requiere ser fortalecido.

El actual marco institucional del país favorece el desarrollo del recurso hídrico exclusivamente para fines sectoriales independientes y hace difícil el desarrollo de proyectos de aprovechamiento de uso múltiple. Una prueba de lo anterior es que los proyectos en operación, concebidos con una visión de uso múltiple, fueron iniciativas tomadas hace más de 40 años (Laguna de Maule, Lago Laja, canal Teno-Chimbarongo). Se infiere que los enfoques sectoriales prevalecientes en Chile podrían significar una pérdida de oportunidades, que sería interesante revertir ${ }^{26}$.

${ }^{26}$ Comisión de Aguas (2011), p. 60. 
Una vez entregados los derechos de aprovechamiento de las aguas a los privados que la solicitan, de acuerdo al Código de Aguas, el Estado ya no vuelve a intervenir, y la reasignación del agua se realiza a través del "mercado de aguas", donde el propietario privado de derechos de agua, los puede arrendar, comprar y vender como cualquier bien inmueble. Este mecanismo de transacción de derechos, favorece una extrema concentración de la propiedad sobre este recurso, recurso en empresas eléctricas, mineras y agroexportadoras, consideradas "motores" del desarrollo nacional; y perjudicando el acceso al agua de la mayoría de la población, sus actividades de subsistencia y a la protección del medio ambiente ${ }^{27}$.

La gestión efectiva de las aguas subterráneas, y de los recursos hídricos en general, que incluya el uso coordinado y conjunto de las aguas superficiales y subterráneas, sumado a la prelación de usos en caso de conflictos entre los diversos usos, requiere una adecuada combinación de Administración Pública, sociedad civil y usuarios. Ello para lograr órganos más eficaces, que han de poder actuar con eficacia e independencia de los avatares políticos ${ }^{28}$.

Se debe estudiar e implementar una solución institucional, que integre en una sola entidad los temas relativos a la gestión de la calidad del agua y los aspectos ambientales asociados al recurso hídrico o, en su defecto, crear coordinaciones institucionales eficaces.

En este contexto, al incorporar la aplicación de experiencias externas comprobadas, considero extremadamente válido profundizar y promover la aplicabilidad de la Gestión Integrada de Cuencas Hidrográficas, como concepto central de una reforma más profunda que reconozca las evidentes diferencias que existen entre las realidades geográficas de las zonas del país. A partir de lo anterior, se puede decir que para que el Estado potencie realmente su capacidad reguladora, resulta indispensable crear nuevas herramientas jurídicas, o al menos complementar en forma significativa la reforma del año 2005. Teniendo presente, además, la distribución de competencias, desde la perspectiva de asignación de roles institucionales, donde la DGA, agencia que integra la Administración, tiene por reconocimiento constitucional la calidad de experto difícilmente rebatible ${ }^{29}$, de conformidad a lo dispuesto en el artículo 38 de la Constitución Política de la República.

La utilización del recurso hídrico, de forma eficiente y sustentable, se presenta como una condición imprescindible para las generaciones presentes, y básica para la existencia de la vida en el futuro, debido a lo cual, se hace necesario contar con

${ }^{27}$ Programa Chile Sustentable (2012). Conflictos por el agua en Chile: urgen cambios legales y constitucionales en las politicas de agua. Santiago, p. 6. Disponible en: <http://www.chilesustentable.net/wp-content/ uploads/2012/12/conflictos_agua_chile_urgen_cambios_dic2012pdf.pdf $>$.

${ }^{28}$ Custodio Gimena, Emilio (2011). “Desafíos para la planificación y gestión del agua subterránea en el siglo XXI”. Congreso Ibérico Aguas Subterráneas: desafíos de la gestión para el siglo XXI, AIH-GE, Zaragoza 2011, Zaragoza: Asociación Internacional de Hidrogeólogos (AIH), pp. 1-21.

${ }^{29}$ Cordero Vega, Luis (2007). "Entre la deferencia, los estándares de control judicial y los procedimientos administrativos". Revista de Derecho Público, No 69, p. 10. 
mecanismos legales que promuevan el manejo integral de cuencas y una gestión integrada de recursos hídricos permitiendo compatibilizar el uso conjunto del agua superficial y subterránea en cuencas hidrográficas.

\section{BiBliografía CITADA}

Banco Mundial (2011). Diagnóstico de la gestión de los recursos hidricos. Departamento de Medio Ambiente y Desarrollo Sostenible.

Bauer, Carl J. (2004). Canto de sirenas, El derecho de aguas chileno como modelo para reformas internacionales. Bilbao: Bakeaz.

COMISIÓN DE AgUAS (2011). Temas prioritarios para una politica nacional de recursos hidricos. Instituto de Ingenieros de Chile.

Cordero Vega, Luis (2006). "Los contratos públicos como medio de intervención y regulación estatal". Revista de Derecho Administrativo Económico, No 17, pp. 31-46.

Cordero Vega, Luis (2007). "Entre la deferencia, los estándares de control judicial y los procedimientos administrativos". Revista de Derecho Público, No 69, pp. 443-453.

Custodio Gimena, Emilio (2011). "Desafíos para la planificación y gestión del agua subterránea en el siglo XXI”. Congreso Ibérico Aguas Subterráneas: desafíos de la gestión para el siglo XXI, AIH-GE, Zaragoza 2011, Zaragoza: Asociación Internacional de Hidrogeólogos (AIH), pp. 1-21.

Donoso, Guillermo; Jouravlev, Andrei; Peña, Humbert y Zegarra, Ernesto (2004). "Mercados (de derechos) de agua: experiencias y propuestas en América del Sur". En: Serie Recursos Naturales e Infraestructura, No 80, CEPAL. Disponible en: <http://www.bvsde.paho.org/bvsaca/fulltext/mercados.pdf> [consulta: 10 noviembre 2011].

Jaeger Cousiño, Pablo (2004). "El innovador derecho de aguas chileno". Revista del Abogado, No 31, pp. 13-15.

López Santa María, Jorge (1998). Los Contratos. Parte general. T. I, Santiago: Editorial Jurídica de Chile.

Montt Oyarzún, Santiago (2002). El dominio público. Estudio de su régimen especial de protección y utilización. Santiago: ConoSur-LexisNexis.

Monroy Cely, Daniel (2003). El mercado de las aguas: la libre transmisibilidad de los derechos de aguas en Chile y su propuesta regulatoria a las demás legislaciones. Memoria para optar al grado de Magíster en Derecho, Facultad de Derecho, Universidad de Chile.

Programa Chile Sustentable (2010). "Marco jurídico para la gestión del agua en Chile: Diagnóstico y Desafíos”, Santiago. Disponible en: <http://www. chilesustentable.net/wp-content/uploads/kalins-pdf/singles/marco-juridicopara-la-gestion-del-agua-en-chile-diagnostico-y-desafios.pdf $>$. 
Programa Chile Sustentable (2012). Conflictos por el agua en Chile: urgen cambios legales y constitucionales en las politicas de agua. Santiago. Disponible en: <http:// www.chilesustentable.net/wp-content/uploads/2012/12/conflictos_agua_chile_urgen_cambios_dic2012pdf.pdf>.

Revesz, Richard (1997). "Foundations of Environmental Law and Policy". Foundation Press, South California: LexisNexis.

RENDIC VÉLIZ, Dinko (2011). Derechos de aguas y pueblos indígenas. Especial referencia a los derechos ancestrales de la Comunidad Indigena de Toconce. Santiago: Librotecnia.

Segura Riveiro, Francisco (2006). Derecho de Aguas. Santiago: LexisNexis.

Vergara Blanco, Alejandro (2007). "Potestades administrativas para denegar solicitudes de derechos de aguas subterráneas y retroactividad”. Revista Chilena de Derecho, Vol. 34, No 1.

\section{NORMAS CITADAS}

Constitución Política de la República.

Código Civil.

Código de Aguas.

Resolución Exenta de la Dirección General de Aguas No 425/2007, que dispone las normas de exploración y explotación de aguas subterráneas

\section{JURISPRUDENCIA CITADA}

Tribunal Constitucional, Rol No 260, 13 de octubre de 1997 (requerimiento sobre la constitucionalidad de preceptos que se señalan en el proyecto modificatorio del Código de Aguas).

Dictamen Contraloría General de la República, No 10969/2003, a requerimiento relativo a solicitudes de derechos de aprovechamiento de aguas subterráneas.

Dictamen Contraloría General de la República, No 56046/2003, a requerimiento relativo a solicitudes de derechos de aprovechamiento de aguas subterráneas.

Dictamen Contraloría General de la República, No 5215/2006, a requerimiento sobre la legislación aplicable aprovechamiento aguas subterráneas. 